\title{
Brucellar epididymo-orchitis in southeastern part of Turkey: an 8 year experience
}

\section{ABSTRACT}

Objective: the different clinical and laboratory features and response to treatment of patients with acute brucellar epididymo-orchitis (BEO) reporting to the reference hospital in Southeastern Anatolia of Turkey. Material and methods: in this study, 27 male patients with brucellosis, who presented with epididymitis or epididymo-orchitis (EO) at the university hospital in Diyarbakir from 1998 to 2006, were included. They were compared with the other male patients. Positive blood culture or high agglutination titers of $\geq 1 / 160$ and positive clinical manifestations of brucellosis were the main criteria for diagnosing brucellosis. Results: fourteen patients had unilateral EO. Leukocytosis was present in 10 patients; all of them had initial agglutination titers of $\geq 1 / 160$ and 10 patients had a positive blood culture. All patients received combined therapy with streptomycin for the first 21 days (or oral rifampicin for 6-8 weeks) with doxycycline or tetracycline for 6-8 weeks. All showed improvement, fever subsided in 3-7 days, and the scrotal enlargement and tenderness regressed. Only one patient had a relapse within one year. Conclusion: in brucellosis-endemic areas, clinicians encountering EO should consider the likelihood of brucellosis. In this study, young age was the most common risk factor, and leukocytosis and high CRP level were the most common laboratory findings. Most cases were unilateral. All patients responded to medical management very well. Conservative management with combination antibiotic therapy was adequate for managing BEO. Conclusively, brucellosis must be considered as a cause of orchitis, especially in endemic regions like Turkey.

Keywords: epididymo-orchitis, brucellosis, Turkey, medical treatment.

[Braz J Infect Dis 2010;14(1):109-115] @Elsevier Editora Ltda.

\section{INTRODUCTION}

Brucellosis is a zoonosis widely distributed worldwide. Millions of individuals are at risk throughout the world, especially in developing countries in which infection in animals is not under control. Although the current incidence of brucellosis in developed countries is low, it occurs sporadically in occupationally exposed groups, including farmers, veterinarians, and laboratory and slaughterhouse workers. ${ }^{1,2}$

Brucellosis is an endemic disease in Turkey. The incidence of this disease in our country is 23 per 100,000 yearly. ${ }^{3}$ It is frequent especially in the rural areas of the middle and southeastern regions, and Brucella melitensis is the most prevalent strain. ${ }^{4}$ The disease typically attacks young and middle-aged adults, with a low incidence among infants and elderly patients. ${ }^{5}$ It has high degree of morbidity for humans, and has caused significant economic loss, representing a serious public health problem in many developing countries. ${ }^{6}$

In humans, brucellosis behaves as a systemic infection with a very heterogeneous clinical spectrum. The most frequent symptoms are fever, chills or rigors, malaise, generalized ache, headache, and fatigue. The prevalence and pattern of complications depend on strain of brucella infecting the individual, age of the patient, and duration of disease. ${ }^{7}$ Gastrointestinal, skeletal, cardiovascular, genitourinary, and hematological manifestations are well known. Neurobrucellosis, peritonitis, pericarditis, and pancytopenia are unusual manifestations of brucellosis. ${ }^{89}$ If the disease is not well recognized and not included in the differential diagnosis, a treatable disease will be missed. ${ }^{9}$

In men, various genitourinary infections including epididymo-orchitis (EO), prostatitis, cystitis, pyelonephritis, interstitial nephritis, exudative glomerulonephritis, renal and tes-
Authors

Mustafa Kemal Celen

Mehmet Ulug ${ }^{2}$

Celal Ayaz ${ }^{3}$

Mehmet Faruk Geyik ${ }^{4}$

Salih Hosoglu ${ }^{5}$

${ }^{1}$ Dicle University Medical School, Department of

Infectious Diseases and

Clinic Microbiology, 21280

Diyarbakir, Turkey.

${ }^{2}$ BSK Anadolu Hospital,

Department of Infectious

Diseases and Clinic

Microbiology, 43100

Kütahya, Turkey.

${ }^{3}$ Dicle University Medical

School, Department of

Infectious Diseases and

Clinic Microbiology, 21280

Diyarbakir, Turkey.

${ }^{4}$ Düzce University Medical

School, Department of

Infectious Diseases and

Clinic Microbiology, 81100

Düzce, Turkey.

${ }^{5}$ Dicle University Medical

School, Department of

Infectious Diseases and

Clinic Microbiology, 21280

Diyarbakir, Turkey.

Submitted on: 07/23/2009 Approved on: 11/08/2009

Correspondence to:

Dr. Mehmet Uluğ

Özel BSK Anadolu

Hastanesi,

Enfeksiyon Hastalıkları

ve Klinik Mikrobiyoloji

Kliniği

Alipaşa Mah. FSM Bulvarı

No: 9, 43100 Kütahya.

Mobile phone: (0532)

4475756, Fax: 0274

2244433 (Hospital)

E-mail: mehmetulug21@

yahoo.com

We declare no conflict of interest. 
ticular abscess, and seminal vasculitis have been attributed to brucellosis. The most frequent genitourinary complication of brucellosis is EO, affecting 2-20\% of males with brucellosis, ${ }^{10-12}$ and it was first described by Hardy as a cause of granulamatous orchitis in $1928 . .^{13,14}$ The testes or epididymis is infiltrated with lymphocytes and plasma cells, and there is an atrophy of the seminiferous tubules. ${ }^{8}$ Although the prognosis of brucellar epididymo-orchitis (BEO) is usually good, delay in diagnosis or inappropriate management may result in serious complications, such as testicular abscess, which may require orchiectomy. ${ }^{10}$

In the present study, the clinical characteristics, treatment, and final outcomes of 27 patients with BEO are presented and compared with male patients without EO.

\section{MATERIAL AND METHODS}

This study was retrospectively carried out at Dicle University Medical Faculty Hospital, Department of Infectious Disease and Clinic Microbiology, between January 1998 and December 2006. Our hospital is the largest (1090 beds) in the city of Diyarbakir in the southeastern Anatolia region of Turkey.

Definitive diagnosis of brucellosis was made by isolation of Brucella spp. from blood cultures. In the absence of positive blood culture, presumptive diagnosis was made serologically by positive serum standard tube agglutination test together with compatible clinical signs and symptoms of brucellosis, such as fever, sweating, arthralgia, hepatomegaly, and splenomegaly. ${ }^{8}$ Among these patients with brucellosis, the diagnosis of epididymitis or EO was based on clinical symptoms (scrotal enlargement, swelling, pain or tenderness not due to other causes), and ultrasonographic examination.

Significant titers were determined to be a Wright's agglutination $\geq 1 / 160$. The following protocol was followed for blood cultures. Two samples of blood (10 mL each) were inoculated into BACTEC bottles and incubated in the non-radiometric semiautomatic BACTEC 9240 system (Becton-Dickinson, Diagnostic Instrument Systems, USA) for 30 days. When a positive bottle was detected, a Gram stain of the broth was performed, and a portion of the fluid was cultured again onto $5 \%$ sheep blood, brucella and eosin-methylene blue agar. These subcultures were incubated at $37^{\circ} \mathrm{C}$ in $5 \% \mathrm{CO}_{2}$ atmosphere for $24-72$ hours. Smears from colonies that grew were stained with Gram stain. The isolates of Gram-negative coccobacilli were identified with use of conventional biochemical tests (e.g., motility; oxidase, catalase, and urease tests; effect to glucose and production of $\mathrm{H}_{2} \mathrm{~S}$ ), and Sceptor system (Becton-Dickinson, Maryland, USA).

Mumps, testicular malignancies, and other bacterial infections were excluded by: absence of history of parotitis, genitourinary tract disease and manipulation, urethral discharge, and sexual exposure; normal serum amy- lase, lipase, alpha-fetoprotein and beta human chorionic gonadotropin levels and negative scrotal ultrasonographic findings compatible with testis tumor.

Based on the systemic disease duration from the beginning to admission to hospital, patients were classified as acute (less than two months), subacute (2-12 months) and chronic (>12 months). ${ }^{16}$ Age, duration of symptoms at admission, history of ingestion of raw milk or milk products, clinical symptoms, results of physical examination, laboratory results, antibiotics administered, and the duration of treatment were recorded. In addition, white blood cell count (WBC), erythrocyte sedimentation rate (ESR), rheumatoid factor (RF), C-reactive protein (CRP), blood chemistry profile, and urine analysis were performed in all patients.

Several approaches were used for treatment in these patients: Tetracycline $(500 \mathrm{mg} / 6 \mathrm{~h} \mathrm{PO})$ or doxycycline (100 $\mathrm{mg} / 12 \mathrm{~h} \mathrm{PO}$ ) for 45 days plus streptomycin $1 \mathrm{~g} /$ day IM) for the first 21 days. Doxycycline $(100 \mathrm{mg} / 12 \mathrm{~h}$ PO) plus rifampicin ( $15 \mathrm{mg} / \mathrm{kg}$ PO) for 45 days. We used both of them in treatment of our patients.

Patients were followed up fortnightly until the end of the treatment period, monthly for three months, and thereafter every three months for one year. Relapse was assessed by a recurrence of symptoms and signs of the disease, a positive blood culture or rising antibody titer after treatment, in the absence of re-exposure to infection.

Data obtained were analyzed using the Statistical Package for the Social Science (SPSS) for Windows, version 11.0 software (SPSS, Chicago, IL, USA). Student's t-test was applied for comparison of means and chi-square test for comparison of proportions. A $p$ value of $<0.05$ was accepted as significant.

\section{RESULTS}

In this study, 302 patients with brucellosis (159 female, 143 male) were analyzed, 27 of them had EO, giving an incidence of EO among males with brucellosis of $18.8 \%$. The clinical characteristics, treatment, and final outcomes of 27 patients with $\mathrm{BEO}$ are compared with male patients without EO $(\mathrm{n}=116)$. The mean age of patients with $\mathrm{BEO}$ and without $\mathrm{EO}$ was $28 \pm 8$ years (range, 16-46) and $36 \pm 14$ years (range, 17-74), respectively. This was statistically significant $(\mathrm{p}=0.005)$. Of the 27 patients with BEO, 51.7\% lived in rural areas and $48.3 \%$ were of urban origin.

An epidemiologic and clinical characteristic of patients with and without EO is shown in Table 1. The presumable infection source could be identified in $78 \%$ of patients with $\mathrm{BEO}$ and $84 \%$ of patients without EO. The possible source of infection was that the patients had consumed unpasteurized dairy products, especially raw milk and fresh cheese, and had direct contact with animals or working with animal products obtained from either sheep or goats. 
Table 1. Epidemiologic and clinical characteristics of patients with and without BEO

\begin{tabular}{|c|c|c|c|}
\hline Variable & $\begin{array}{c}\text { Patients with BEO } \\
(\mathbf{n}=27) \\
\mathbf{n}(\%)\end{array}$ & $\begin{array}{l}\text { Patients without BEO } \\
(\mathrm{n}=116) \\
\mathrm{n}(\%)\end{array}$ & p value \\
\hline Mean age (year) \pm SD & $28.26 \pm 8.42$ & $36.39 \pm 14.24$ & 0.005 \\
\hline Clinical type & & & 0.285 \\
\hline Acute & $22(81.8)$ & $77(66.4)$ & \\
\hline Subacute & $4(14.8)$ & $27(23.2)$ & \\
\hline Chronic & $1(3.7)$ & $12(10.4)$ & \\
\hline Mean admission time (day) \pm SD & $11.78 \pm 7.28$ & $10.23 \pm 5.89$ & 0.244 \\
\hline \multicolumn{4}{|l|}{ History } \\
\hline Ingesting raw milk/ Fresh cheese & $21(77.7)$ & $90(77.5)$ & 0.983 \\
\hline Ingesting raw meat balls & $4(14.8)$ & $26(22.4)$ & 0.382 \\
\hline Animal contact & $2(7.4)$ & $20(17.2)$ & 0.202 \\
\hline Family history brucellosis & $2(7.4)$ & $14(12)$ & 0.489 \\
\hline Laboratory workers & 0 & $3(2.5)$ & 0.398 \\
\hline Unknown transmission & $6(22.2)$ & $18(15.5)$ & 0.401 \\
\hline \multicolumn{4}{|l|}{ Symptoms } \\
\hline Abdominal pain & $25(92.5)$ & $14(12)$ & $<0.0001$ \\
\hline Fever & $24(88.8)$ & $102(87.9)$ & 0.890 \\
\hline Malaise/ Weakness & $22(81.4)$ & $78(67.2)$ & 0.146 \\
\hline Arthralgia & $20(74)$ & $99(85.3)$ & 0.158 \\
\hline Myalgia & $19(70.3)$ & $90(77.5)$ & 0.428 \\
\hline Sweating & $19(70.3)$ & $86(74.1)$ & 0.690 \\
\hline Lumbar pain & $17(62.9)$ & $88(75.8)$ & 0.172 \\
\hline Chills & $16(59.2)$ & $84(72.4)$ & 0.179 \\
\hline Lack of appetite & $13(48.1)$ & $92(79.3)$ & 0.001 \\
\hline Headache & $10(37)$ & $71(61.2)$ & 0.022 \\
\hline Vomiting & $4(14.8)$ & $23(19.8)$ & 0.549 \\
\hline Rash & $2(7.4)$ & 17 (14.6) & 0.318 \\
\hline Jaundice & $1(3.7)$ & $17(14.6)$ & 0.122 \\
\hline Cough & $1(3.7)$ & $18(15.5)$ & 0.103 \\
\hline Constipation & $1(3.7)$ & $21(18.1)$ & 0.062 \\
\hline Depression & $1(3.7)$ & $1(0.8)$ & 0.257 \\
\hline Diarrhea & 0 & $4(3.4)$ & 0.328 \\
\hline Scrotal pain & $27(100)$ & 0 & \\
\hline Scrotal redness & $24(88.8)$ & 0 & \\
\hline Scrotal swelling & $21(77.7)$ & 0 & \\
\hline Dysuria & $6(22.2)$ & 0 & \\
\hline Frequent urination & $2(7.4)$ & 0 & \\
\hline Haematuria & $1(3.7)$ & 0 & \\
\hline \multicolumn{4}{|l|}{ Signs } \\
\hline Hepatomegaly & $6(22.2)$ & $32(27.5)$ & 0.570 \\
\hline Splenomegaly & $4(14.8)$ & $28(24.1)$ & 0.295 \\
\hline Lymphadenopathy & $2(7.4)$ & $13(11.2)$ & 0.562 \\
\hline Meningitis & 0 & $8(6.8)$ & 0.160 \\
\hline Pleural effusion & 0 & $5(4.3)$ & 0.272 \\
\hline Carditis & 0 & $3(2.5)$ & 0.398 \\
\hline Usage of antibiotic before admission & $10(37)$ & $29(25)$ & 0.621 \\
\hline
\end{tabular}

(SD: standard deviation) 
No source was identified in six patients $(22.2 \%)$ with BEO and 18 patients (15.5\%) without EO. When the distribution of all cases was examined according to months of the year, an increase was seen in May (Figure 1). There were no significant differences in the distribution of months among any of them.

Of the 27 patients with BEO, the onset of symptoms was acute in 22 patients $(81.8 \%)$, subacute in four patients $(14.8 \%)$, and chronic in one patient $(3.7 \%)$. The mean admission time was $11.8 \pm 7.3$ days in patients with $\mathrm{BEO}$ and $10.2 \pm 5.9$ days in patients without $\mathrm{EO}$, which is not statistically significant $(\mathrm{p}=0.244)$. The symptoms reported at admission are shown in Table 1. None of the patients was asymptomatic. Fever, scrotal pain and swelling, and scrotal redness were the most common symptoms. Headache, lack of appetite, abdominal pain were seen in patients with $\mathrm{BEO}$ more than without EO ( $\mathrm{p}=0.022, \mathrm{p}=0.001, \mathrm{p}<0.0001$ respectively). Urinary symptoms (dysuria, haematuria, frequency or urgency) were seen in six patients (22.2\%).

Laboratory findings of patients are shown in Table 2. ESR, WBC, and CRP levels were measured in all patients. ESR ranged from $9-81 \mathrm{~mm} / \mathrm{h}$ (median, $44 \mathrm{~mm} / \mathrm{h}$ ), 25 patients (92.9\%) had ESR $>20 \mathrm{~mm} / \mathrm{h}$ and two had ESR $<20 \mathrm{~mm} / \mathrm{h}$. CRP levels were high (mean $71 \pm 21.7 \mathrm{mg} / \mathrm{dL}$; range, 9-140
Figure 1: Distribution of BEO by months of the year.

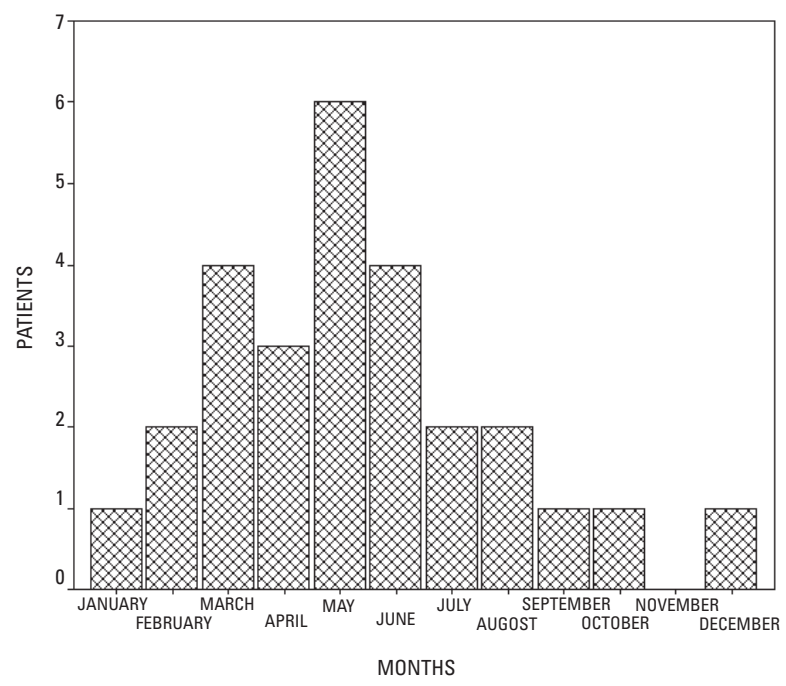

$\mathrm{mg} / \mathrm{dL}$ ) in 26 patients with BEO. Leukocytosis ( $\geq 10200$ $\left.\mathrm{WBCs} / \mathrm{mm}^{3}\right)$ was found in 10 patients $(37 \%)$ and leucopenia $\left(<4600 \mathrm{WBCs} / \mathrm{mm}^{3}\right)$ in two patients $(7.4 \%)$. Thrombocytopenia $\left(<142000\right.$ platelets $\left./ \mathrm{mm}^{3}\right)$ was discovered in six patients $(22.2 \%)$. Urine analysis was available before

Table 2. Hematological findings of patients with and without BEO

\begin{tabular}{|c|c|c|c|}
\hline Variable & $\begin{array}{l}\text { Patients with BEO } \\
\qquad \begin{array}{c}(\mathrm{n}=27) \\
\mathbf{n}(\%)\end{array}\end{array}$ & $\begin{array}{l}\text { Patients without BEO } \\
\qquad \begin{array}{c}(\mathrm{n}=116) \\
\mathrm{n}(\%)\end{array}\end{array}$ & $p$ value \\
\hline $\mathrm{WBC} / \mathrm{mm}^{3}$ & & & $<0.0001$ \\
\hline$<4600$ & $2(7.4)$ & $22(19)$ & \\
\hline $4600-10200$ & $15(55.6)$ & $84(72.4)$ & \\
\hline $10200<$ & $10(37)$ & $10(8.6)$ & \\
\hline Hematocrit $<37.7 \mathrm{~g} / \mathrm{dL}$ & $10(37)$ & $40(34.5)$ & 0.802 \\
\hline Platelet $<142000$ & $6(22.2)$ & $26(22.4)$ & 0.983 \\
\hline $\mathrm{ALT}>45 \mathrm{IU} / \mathrm{L}$ & $9(33.3)$ & $42(36.2)$ & 0.779 \\
\hline $\mathrm{AST}>45 \mathrm{IU} / \mathrm{L}$ & $8(29.6)$ & $41(35.3)$ & 0.573 \\
\hline GGT $>80 \mathrm{IU} / \mathrm{L}$ & $4(14.8)$ & $10(8.6)$ & 0.329 \\
\hline ALP > 279 IU/L & $5(18.5)$ & $23(19.8)$ & 0.877 \\
\hline Total bilirubin $>1.2 \mathrm{mg} / \mathrm{dL}$ & $8(29.6)$ & $22(19)$ & 0.220 \\
\hline Ferritin > 220ng/mL & $7(25.9)$ & $28(24.1)$ & 0.846 \\
\hline $\mathrm{CK}>226 \mathrm{IU} / \mathrm{L}$ & $1(3.7)$ & $9(7.8)$ & 0.457 \\
\hline $\mathrm{ESR}>20 \mathrm{~mm} / \mathrm{h}$ & 25 (92.6) & $16(13.8)$ & 0.368 \\
\hline $\mathrm{CRP}>8 \mathrm{mg} / \mathrm{dL}$ & $26(96.3)$ & $87(75)$ & 0.014 \\
\hline Positive RF & $1(3.7)$ & $7(6.3)$ & 0.538 \\
\hline Positive blood culture & $10(37)$ & $42(36.2)$ & 0.936 \\
\hline Positive urine culture & 0 & 0 & \\
\hline
\end{tabular}

(ALT: alanine aminotransferase, AST: aspartate aminotransferase, ALP: alkaline phosphatase,

GGT: $\gamma$-glutamyl transpeptidase, CK: creatine kinase, RF: rheumatoid factor) 
treatment in all cases; in six, the analysis was abnormal. All patients underwent the Rose-Bengal test; the results were positive for all of them. Also standard tube agglutination testing of initial samples was carried out in all patients and all of them were positive for brucella antibodies (titer, $\geq 1 / 160$ ). Two or more blood cultures were drawn under ideal conditions in 17 patients (62.9\%). Cultures of blood specimens from 10 (37\%) of the 27 patients with EO were positive for Brucella spp. and 12 patients with negative blood cultures had received antibiotic therapy previously. Routine urine cultures were taken from all patients in order to rule out other genitourinary infections. No growth was detected in urine cultures.

When we compared clinical and laboratory findings of the patients; young age, high CRP level, and leukocytosis were statistically significant $(\mathrm{p}=0.005, \mathrm{p}=0.014, \mathrm{p}<0.0001$ respectively).

Scrotal ultrasonography was performed on all patients. Of the 27 patients, 14 patients (51.8\%) had unilateral involvement of testis and epididymis, seven patients had unilateral involvement of testis and only four had unilateral involvement of epididymis. Two patients had bilateral involvement. Testis enlargement was found in 10 patients, and six presented hydrocele. Increased vascularization was detected in 22 patients $(81.8 \%)$.

All patients received combined antibiotic therapy. Before the diagnosis of BEO, four patients $(14.8 \%)$ were treated with different antimicrobial treatments. Eight patients (29.6\%) had been given antibiotic for brucellosis before admission. Once the diagnosis was correctly established, all the patients were treated for 45 days. Duration of therapy varied according to clinical response and the presence of focal disease. A total of 16 patients (59.2\%) received a combination of orally administered doxycycline $(200 \mathrm{mg} /$ day $)$ for 6-8 weeks plus streptomycin ( $1 \mathrm{~g} /$ day) for the initial 21 days. Eleven patients $(40.8 \%)$ received a combination of doxycycline $(200 \mathrm{mg} /$ day $)$ plus rifampicin $(600-900 \mathrm{mg} /$ day $)$ for 6-8 weeks. There was an improvement in all patients; the fever subsided in 3-7 days, and there was local regression of the scrotal enlargement.

For the 20 patients who were admitted as inpatients, the median duration of hospital stay was $9.1 \pm 4.2$ (range, 5-21) days; most (17 patients, $62.9 \%$ ) stayed for 6-10 days and four patients $(14.8 \%)$ had a hospital stay of $>10$ days. Orchiectomy was not required for any of the patients. Relapse occurred in one patient who was discontinuing his therapy.

\section{DISCUSSION}

The incidence of brucellosis has increased during recent years due to the inability to complete its eradication among the animals of Turkey, especially sheep and goats. ${ }^{4}$ In our region the most common etiological agent for brucellosis is $B$. melitensis. ${ }^{17}$ Our hospital is located in southeastern Anatolia of Turkey, where the majority of the population usually con- sumes unpasteurized dairy products collected from villages.

Human brucellosis is diagnosed on the basis of epidemiological and clinical findings, and bacteriological and serological tests. Symptoms of the disease may mimic many of the disease and show varied manifestations of acute and chronic infection. Complications of brucellosis sometimes may lead to misdiagnosis.

Genitourinary involvement is rare and EO is one of the manifestations of brucellosis. Brucellosis is a relatively common cause of $\mathrm{BEO}$ in geographic areas where $B$. melitensis is endemic. ${ }^{18}$ The incidence of BEO is estimated at $2-20 \%{ }^{10,11,14}$ In the endemic regions this rate is high, ${ }^{14,19}$ Khan et al..$^{20}$ reported that $35 \%$ of the cases of EO in their series were caused by brucellosis. Patil et al..$^{21}$ reported a rate of $6 \%$ and the studies from Turkey reported that the rate was 5.5\% and $12.7 \%$ in their series, respectively. ${ }^{18,22}$ In another study Khan investigated 100 patients with brucellosis and found a rate of $6 \% .{ }^{23}$ In the present study, EO occurred in $8.9 \%$ of all patients and in $18.8 \%$ of the male patients with brucellosis. This result was similar to that reported by others. ${ }^{22-24}$

When the distribution of cases according to the months of the year was examined, an increase was seen in the spring and summer months, possibly due to increased consumption of milk and fresh cheese in spring. Several studies have reported a seasonal variation in brucellosis in Turkey. ${ }^{4,17}$ As can be seen in Figure 1, of the 27 patients with BEO, 77.7\% were seen in spring and summer.

Brucellosis can occur at any age but the most common age group involve adolescents and young adults. ${ }^{12,17}$ In the present study, the mean age of patients with EO was 28.2 years and they were significantly younger than the patients without EO, and this was similar with other studies. ${ }^{11,13,14,20,22}$ It appears that BEO occurs most commonly in young males. This result clearly shows how the age range reflects the magnitude of the socio-economic and cultural impact of brucellosis in our region and in Turkey.

Most of our patients $(81.8 \%)$ had an acute brucellosis when EO occurred and this was similar with other studies, ${ }^{11,13,22}$ except one. ${ }^{25}$ Scrotal pain and swelling, scrotal redness and fever were the most common symptoms and these were similar to the literature. ${ }^{11,13,20,22,25}$ Urinary symptoms were seen in $22.2 \%$ of our patients, this rate was $31 \%$ in Colmenero et al., ${ }^{2} 47 \%$ in Akinci et al., ${ }^{22}$ and $69 \%$ in Kahn et al..$^{20}$ studies. On the other hand, the rate was lower in other studies. ${ }^{10,11,13,25}$

Abnormal blood test results are usually mild and nonspecific. The hemoglobin level may be lower as a result of prolonged infection, and a moderately elevated ESR is found in most cases. Liver function tests disclose a mild to moderate increase in the hepatic transaminases serum levels. ${ }^{11}$ Leukocytosis and high CRP levels are the significant laboratory findings in our study. Leukocytosis has been usually reported as not being a typical feature of brucellosis, but 
it was presented as an important feature of BEO in some studies. ${ }^{20,26}$ On the other hand, leukocytosis was detected at lower rates in some studies. ${ }^{10,13,22}$ High CRP level is also significant in Akinci et al. study. ${ }^{22}$ However, as far as we know, no studies have investigated CRP level except this study in the literature.

Since most patients had used antibiotics effective on brucella infection before they were admitted to our hospital, the rate of isolation of microorganism from blood culture was found to be low. Only $37 \%$ of our patients had positive culture for Brucella spp., mostly being B. melitensis. This rate was similar to Yurdakul et al. ${ }^{10}$ study, but lower than the other studies. ${ }^{2,11,22,24}$

This study was not designed to analyze the ultrasound features of BEO but ultrasonography plays an important role in the diagnosis, assessment, and management of patients. ${ }^{26}$ It is useful to enable the exclusion of the possibility of abscess or tumor before establishing the primary clinical diagnosis. Unilateral EO is the most common genitourinary complication of brucellosis. Infection that is limited to the testis is rare; the epididymis is usually involved in patients who have acute inflammation. Of the 27 patients, $92.5 \%$ had unilateral involvement and most of them had EO. This result were compatible with the literature. ${ }^{11,13,14,20,22,27,28}$

The percentage of therapeutic failure or relapse ranges from $0 \%$ to $40 \%{ }^{10,11,13,20}$ and the need for orchiectomy from $0 \%$ to $5.1 \% .^{10,11,13,24}$ The overall percentage of therapeutic failure or relapse in the present study was 3.7\%, with no patient requiring surgery. Our results were similar to the literature. On the other hand, we did not find significant differences in the rate of therapeutic failure or relapse between the patients treated with doxycycline plus streptomycin and those treated with doxycycline plus rifampicin, as in the other studies. ${ }^{2,11}$

\section{CONCLUSION}

The frequency of brucella complications is variable in different age groups in Turkey. The most frequent complication of brucellosis is osteoarticular, followed by cutaneous, genitourinary, nervous, and other complications. Brucellosis must be considered as a cause of orchitis in especially endemic regions like Turkey. Unilateral EO is the most common genitourinary complication and most of the cases occur between the second and third decade. Headache, lack of appetite, abdominal pain, leukocytosis and high CRP levels are the significant findings. All patients respond to medical management very well.

Since brucellosis is a preventable disease, knowledge and early diagnosis of the complications are especially important. Therefore, population education and medical precautions are necessary to prevent the harmful effects of brucella and its complications. In addition, primary health care physicians in endemic regions must recognize that brucellosis is an infection which may involve almost any organ system and which may vary markedly in its clinical presentation.

\section{ACKNOWLEDGEMENTS}

The authors gratefully acknowledge the technical assistance of Dr. Nuray Can Ulug and thank Fehmi Özturan for his help with the English language version of the text.

\section{REFERENCES}

1. Corbel MJ. Brucellsis: an overview. Emerg Infect Dis 1997; 3:213-21.

2. Colmenero JD, Munoz-Roca NL, Bermudez P, Plata A, Villalobos A, Reguera JM. Clinical findings, diagnostic approach, and outcome of Brucella melitensis epididymo-orchitis. Diagn Microbiol Infect Dis 2007; 57:367-72.

3. URL: http://www.saglik.gov.tr/extras/istatistikler/temel2004/ tablo52.htm

4. Gur A, Geyik MF, Dikici B et al. Complications of brucellosis in different age groups: a study of 283 cases in southeastern Anatolia of Turkey. Yonsei Med J 2003; 44:33-44.

5. Wise RI. Brucellosis in the United States: past, present and future. JAMA 1980; 244: 2138-42.

6. Kadri SM, Rukhsana A, Laharwal MA, Tanvir M. Seroprevalence of brucellosis in Kashmir (India) among patients with pyrexia of unknown origin. J Indian Med Assoc 2000; 98:170-1.

7. Memish Z, Mah MW, Al Mahmoud S, Al Shaalan M, Khan MY Brucella bacteraemia: Clinical and laboratory observations in 160 patients. J Infect 2000; 40:59-63.

8. Young EJ. Brucella species. In Mandell GL, Bennet GE, Dolin R eds. Principles and Practice of Infectious Diseases. Philadelphia: Churchill Livingstone; 2000:2386-93.

9. Hatipoglu CA, Yetkin A, Ertem GT, Tulek N. Unusual clinical presentation of brucellosis. Scand J Infect Dis 2004; 36:694-7.

10. Yurdakul T, Sert U, Acar A, Karalezli G, Akcetin Z. Epididymoorchitis as a complication of brucellosis. Urol Int 1995; 55:141-2.

11. Navarro-Martinez A, Solera J, Corredoira J et al. Epididymoorchitis Due to Brucella melitensis: a retrospective study of 59 patients. Clin Infect Dis 2001; 33: 2017-22.

12. Colmenero JD, Reguera JM, Martos F et al. Complications associated with Brucella mellitensis infection: a study of 530 cases. Medicine 1996; 75:195 211.

13. Memish ZA, Venkatesh S. Brucellar epididymo-orchitis in Saudi-Arabia: a retrospective study of 26 cases and review of the literature. BJU Int 2001; 88:72-6.

14. Kadikoylu G, Tuncer G, Bolaman Z, Sina M. Brucellar orchitis in Inner west Anatolia Region of Turkey. A report of 12 cases. Urol Int 2002; 69:33-5.

15. Ozturk R, Mert A, Kocak F et al. The diagnosis of brucellosis by use of BACTEC 9240 blood culture system. Diagn Microbiol Infect Dis 2002; 44:133-5

16. Khateeb MI, Araj GF, Majeed SA, Lulu AR. Brucella arthritis: study of 96 cases in Kuwait. Ann Rheum Dis 1990; 49:994-8.

17. Geyik MF, Gur A, Nas K et al. Musculoskeletal involvement of brucellosis in different age groups: a study of 195 cases. Swiss Med Wkly 2002; 132:98-105. 
18. Ertek M, Yazgi H, Kadanali A, Ozden K, Tasyaran MA. Complications of Brucella infection among adults: An 18 year retrospective evaluation. Türk J Med Sci 2006; 36(6):377-81.

19. Hasanjani MR, Mohrez M, Smailnejad SM, Soleimani MJ, Hajiahmadi M. Epidemiological features and clinical manifestations in 469 adult patients with brucellosis in Babol, northern Iran. Epidemiol Infect 2004; 132:11014.

20. Khan MS, Humayoon MS, Al Manee MS. Epididymo-orchitis and brucellosis. Br J Urol 1989; 63: 87-9.

21. Patil CS, Hemashattar BM, Nagalotimah SJ. Genito-urinary brucellosis in man. Indian J Pathol Microbiol 1986; 29:364-7.

22. Akinci E, Bodur H, Cevik MA et al. A complication of Brucellosis: Epididymo-orchitis. Int J Infect Dis 2006; 10:171-7.
23. Khan MY. Brucellosis: Observations on 100 patients. Ann Saudi Med 1986; 6:19-23.

24. Papatsoris AG, Mpadra FA, Karamokzis MV, Frangides CY. Endemic brucellar epididymo-orchitis: A 10 year experience. Int J Infect Dis 2002; 6:309-13.

25. Ibrahim AI, Awad R, Shetty SD, Saad M, Bilal NE. Genito-urinary complications of brucellosis. Br J Urol 1988; 61:294-8.

26. Afsar H, Baydar J, Sirmatel F. Epididymo-orchitis due to brucellosis. Br J Urol 1993; 72:104 5.

27. Patel PJ, Kolawole TM, Sharma N et al. Sonographic findings in scrotal brucellosis. J Clin Ultrasound 1988; 16:483-6.

28. Bayram MM, Kervancioglu R. Scrotal gray-scale and color Doppler sonographic findings in genitourinary brucellosis. J Clin Ultrasound 1997; 25:443-7. 